\title{
VAIKUૃ IR PAAUGLIŲ NERIMO SUTRIKIMAI ŠEIMOS GYDYTOJO PRAKTIKOJE
}

\author{
Kotryna Tarasevičiūtė, Gertrūda Poškutė \\ Lietuvos sveikatos mokslu universiteto Medicinos fakultetas
}

Raktažodžiai: vaikai, paaugliai, medikamentai, psichoterapija, nerimo sutrikimai, baimè.

\begin{abstract}
Santrauka
Vaikų ir paauglių nerimo sutrikimai yra dažni ir linkę kartotis. Negydomi jie lètina socioemocinę ir pažintinę raidą. Šeimos gydytojo praktikoje itin svarbu juos anksti atpažinti ir imtis tinkamų veiksmų. Tyrimo tikslas - pateikti šeimos gydytojui dažniausių pediatrinių pacientų nerimo sutrikimų atpažinimo ir gydymo gaires, reikalingas norint ankstyvos intervencijos pagalba išvengti besivystančių pasekmių. Literatūros ieškota elektroninėse duomenų bazèse Medline (Pubmed), Cohrane Library, specializuotoje paieškos sistemoje Google Scholar. Tyrimo rezultatai ir išvados. Norint diagnozuoti nerimo sutrikimą, būtina įvertinti rizikos veiksnius, aplinkybes, situacijas bei šeimos kontekstą, kuriame jis pasireiškia. Svarbu atskirti normalų vaikų baimių vystymąsi ir atpažinti patologinį nerimą, kuris trikdo kasdienę veiklą ir stabdo normalią raidą. Šeimos gydytojas, įtaręs ar nustatęs nerimo sutrikimą, gali kreiptis ị kitus sveikatos priežiūros specialistus arba, vadovaudamasis šeimos gydytojo norma, skirti gydymą. Tiriamos veiksmingos šių patologijų intervencijos, tokios kaip psichoterapija, psichofarmakoterapija. Kognityviné elgesio terapija įrodyta kaip veiksminga patologinio nerimo pasireiškimo korekcijai ir neturinti nepageidaujamo poveikio. Vis dèlto, kartais reikia skirti medikamentinị gydymą. Selektyvūs serotonino reabsorbcijos inhibitoriai (SSRI) priskiriami prie pirmos eilès medikamentų dèl teigiamo naudos ir žalos santykio. Valstybinè vaistų kontrolès tarnyba prie Lietuvos Respublikos sveikatos apsaugos ministerijos yra ịspejusi dèl galimos SSRI gydymo sukeltos suicido rizikos, elgesio pakitimų bei somatinių nusiskundimų. Renkantis medikamentinę gydymo formą, reikètų įspèti paciento tèvus apie galimą šalutini poveikị ir gauti sutikimą gydymui.
\end{abstract}

\section{Ivadas}

Nerimo sutrikimai - vieni dažniausių psichiatrinių sutrikimų, pasireiškiančių vaikams ir paaugliams iki 18 metų [1]. Jų paplitimas tarp pediatrinių pacientų varijuoja nuo 15 iki 20 procentų [2,3]. Labiausiai paplitusios nerimo būklès yra specifinès fobijos, socialinè fobija, generalizuotas nerimo sutrikimas ir atsiskyrimo baimè [2]. Šie bei kiti vaikystejje pasireiškiantys nerimo sutrikimai gali būti ir sunkesnių psichiatrinių ligų psichopatologijos dalis [4]. Vaikų ir paauglių nerimo sutrikimai dažnai susiję su reikšmingu dalyvumo sumažèjimu, psichologinio brendimo sutrikdymu ir suicido rizikos padidejjimu [5]. Dèl nerimo būklių keliamų pojūčių itin dažnai kreipiamasi ị gydytojus, dirbančius pirminèje sveikatos priežiūros grandyje [1]. Nustatyta, kad trečdaliui pacientų negydomi nerimo sutrikimai tęsiasi ilgai, persipina su kitais sutrikimais ir ịgauna sudetingesnę formą, trečdaliui vėlesniame amžiuje pereina ị depresiją ir piktnaudžiavimą kenksmingomis medžiagomis [6].

Tyrimo tikslas - vaikų ir paauglių nerimo sutrikimų rizikos veiksnių, diagnostikos bei galimų gydymo taktikų aptarimas ir rekomendacijos šeimos gydytojui.

\section{Tyrimo medžiaga ir metodai}

Literatūros šaltinių ieškota elektroninèse duomenų bazėse Medline (Pubmed), Cohrane Library, specializuotoje paieškos sistemoje Google Scholar, naudojantis raktinių žodžių grupėmis ir juos kombinuojant. Remtasi Lietuvos Respublikos sveikatos apsaugos ministerijos svetainejje pateiktais teisiniais dokumentais.

\section{Tyrimo rezultatai}

Rizikos veiksniai. Vaikystės ar paauglystės laikotarpiu diagnozavus nerimo sutrikimus, padidèja ịvairių jų formų pasikartojimo tikimybè vèlesniais augimo periodais ir suaugus [7]. Šių sutrikimų rizikos veiksnių atpažinimas bei savalaikè intervencija yra viena veiksmingiausių priemonių užkirsti kelią jų išsivystymui [8]. Nerimo sutrikimų išsivystymo rizika priklauso nuo asmens emocinio ir kognityvinio 
vystymosi ypatumų [6]. Vaikams, kurių atsakas į dažniausiai pasitaikančias situacijas ir stresorius yra neadaptyvus, būdinga didesnè nerimo sutrikimo išsivystymo rizika [8]. Atliktuose tyrimuose nustatyta, kad nerimastingi vaikai neutralius ir nepavojingus stimulus yra linkę suvokti kaip grèsmingus, o saugius ir pavojingus - asocijuoti tarpusavyje. Jiems būdingas padidintas jautrumas apdovanojimui už pastangas bei stipresnis susirūpinimas dèl bendraamžiu vertinimo [6]. Nemažiau svarbūs ir kiti rizikos veiksniai, tokie kaip: vaiko introversija, polinkis ị elgesio slopinimą, negatyvūs patyrimai, žema savivertè ir akademiniai pasiekimai, šeimos nariu psichopatologija, nesaugi aplinka [8]. Užsienyje atliktose studijose nustatyta, jog kiekvienai vaiko vystymosi stadijai galima priskirti atskirus tik jai būdingus rizikos veiksnius, kuriais remiantis galima nuspèti nerimo sutrikimų pasireiškimo riziką. Tarp tokių veiksnių minimi mažesnis nei 7 balų naujagimio ịvertis Apgar skalèje ar 5 metus po vaiko gimimo besitęsiantis nuolatinis motinos distresas [7]. Paauglystės laikotarpiu moteriškoji lytis yra pažeidžiamesnè nerimo sutrikimų išsivystymo atžvilgiu, kadangi šios lyties atstovès yra siejamos su stipresniu reagavimu bei didesniu jautrumu kūno formų, kognityvinès ir emocinès sferos pokyčiams. Rizikos veiksniai, tokie kaip žemas šeimos socioekonominis statusas, tèvų atstūmimas, skurdūs streso valdymo ịgūdžiai šiuo periodu ypač stipriai veikia ir dažnina nerimo sutrikimus [9].

Nerimo sutrikimų diagnostika. Nerimo sutrikimų diagnostika paremta klinikiniu ištyrimu [10]. Nerimastingi vaikai, patekę pas šeimos gydytoją, gali skųstis pasikartojančiais galvos skausmais ar skrandžio ir žarnyno veiklos sutrikimais, kurių tikroji priežastis yra patologinis nerimas [11]. Somatiniai susirgimai, tokie kaip hipertiroidizmas, gali pamėgdžioti nerimo sutrikimus, todèl pirmiausia reikètų ekskliuduoti galimas organines patologijas. Svarbu atskirti normalų įvairių baimių vystymąsi nuo patologinio. Dèl to yra apibrezžti normalios vaikų psichologinès raidos aspektai [12]. Normalios raidos atveju, kūdikysteje, tarp 8-12 mènesio, atsiranda atsargumas ir drovumas, esant nepažistamų žmonių. Tarp 10-18 mėnesio vaikai patiria reikšmingą nerimą, susijusị su atsiskyrimu nuo artimuju. Šios baimès turètu sumažèti, jiems sulaukus 2-3 metų [10]. Intervencija reikalinga, jeigu dèl nerimo vaikas vengia svarbių socialinių patirčių ir tai lètina jo socioemocinę bei pažintinę raidą [13]. Ikimokykliniam ir mokykliniam amžiui būdingos specifinès baimès, tokios kaip: meteoritu, pasaulio pabaigos, kraujo, mirties, tamsos, vabzdžių, ligos, bakterijų, mokyklos, viešo pasirodymo. Jos gali būti priskiriamos patologinių baimių kategorijai tuo atveju, jeigu kelia ryškų distresą [10]. Irzlumas ir pykčio protrūkiai gali būti interpretuojami kaip prieštaravimo ar nepaklusnumo simptomai, tačiau tokiu būdu vaikas iki 12 metų gali bandyti išvengti subjektyvių neigiamų impulsų $[11,12]$. Normaliam psichologiniam vystymuisi būdingos baimès paprastai mažèja vaikui augant, tačiau paauglystėje dèl socialinio identiteto pokyčių susiduriama su kitomis šiam laikotarpiui būdingomis problemomis - padidejjusiu jautrumu neigiamam vertinimui, bendraamžių atstūmimu ir socialiniu nerimu [10]. Dèl šios priežasties reikia išlikti itin budriems, kad būtų išvengta sociofobijos išsivystymo [13]. Akademinių rezultatų nuosmukis gali byloti apie nerimo sutrikimo vystymąsi - dèl nerimo būkliu vaikai ir paaugliai pradeda praleisti pamokas, nepaisant kognityvinių galimybių, jiems gali nesisekti mokytis. Tai sutrikdo tolimesni vaiko ir paauglio socioekonomini vystymąsi, sukelia finansiniu sunkumų ateityje [11].

Pagalba esant nerimo sutrikimų. Lietuvos medicinos normoje MN 14:2019 „Šeimos gydytojas“ fobinių ir kitų nerimo sutrikimų įtarimas, diferencijavimas, diagnozavimas ir gydymas, prireikus pasitelkiant kitus asmens sveikatos priežiūros specialistus, priskiriami šeimos gydytojo kompetencijai [14]. Šeimos gydytojui svarbu pabrěžti ankstyvos intervencijos svarbą ir nukreipti šeimą tinkamam gydymui. Nerimo spektro sutrikimų korekcijai taikomos medikamentinès ir nemedikamentinès priemonès. Remiantis dešimties metų studijomis, vaikams ir paaugliams pritaikyta kognityvinè elgesio terapija yra efektyvi nerimo sutrikimu gydymo nemedikamentinè priemone [15]. Šios terapijos vaikams nuo 4 iki 7 metų užsièmimus gali būti rekomenduojama lankyti kartu su tèvais [16]. Egzistuoja veiksmingos tyrimais irodytos kognityvinès elgesio terapijos technikos, tokios kaip: psichoedukacija, relaksacijos technikos, mąstymo ir reakcijos i stresogeninị veiksnị korekcija, tiesioginio susidūrimo su nerimą keliančiu objektu pratimai [15].

Medikamentinis gydymas. Paskaičiuota, kad psichoterapiniu gydymu nerimo sutrikimų remisija pasiekiama apie 60 proc. atvejų [17]. Pacientai labai skirtingai reaguoja ị ịvairias intervencijas ir kol kas nèra sukurta bendro modelio atsakui i gydymą nuspèti, todèl reikalingas pastovus gydymo efektyvumo konkrečiu atveju stebejjimas [15]. Sunkesnių nerimo būkliu atvejais tenka skirti medikamentus arba kombinuoti juos su nemedikamentiniu gydymu. Apie psichofarmakoterapiją galima svarstyti, kai simptomai atitinka diagnostinius trukmès ir intensyvumo kriterijus, nurodytus TLK-10-AM klasifikacijoje. Remiantis pastarujų metų studijomis, selektyvieji serotonino reabsorbcijos inhibitoriai (SSRI) priskiriami pirmo pasirinkimo antidepresantu grupei (pvz., Sertraline), gydant pediatrinių pacientų atsiskyrimo, generalizuota, socialinio nerimo sutrikimus [15, 18-21]. Skiriant reikia žinoti ir dažniausią galimą nepageidaujamą poveikị, tokį kaip galvos ir pilvo skausmai, nemiga bei ankstyvo nutraukimo rizika [15]. Norint išvengti ankstyvo medikamentinio gydymo nu- 
traukimo, svarbu edukuoti šeimą apie šiuos nepageidaujamus reiškinius, gydymo trukmę ir gauti jų sutikimą. Minimali vartojimo trukmè turètų būti bent 6-8 savaitès, kad galima būtų ịvertinti vaisto efektyvumą [22]. Šeimos gydytojui reikia atidžiai stebèti pediatrinį pacientą dèl galimų suicidinių apraiškų, priešiškumo (daugiausia agresijos, priešinimosi, neklusnumo ir pykčio), sulètejusio augimo ar brendimo. Šiems reiškiniams pasireiškus SSRI vartojimo fone, reikalinga gydymo korekcija [18, 23].

\section{Išvados}

1. Šeimos gydytojas, susidūręs su vaiko ar paauglio iki 18 metų reikšmingu distresu, autonomine disfunkcija bei gyvenimo kokybės pablogejjimu dèl patologinių baimių, turètų ịtarti galimą nerimo sutrikimą.

2. Noredamas kuo anksčiau ir tiksliau įvertinti nerimo sutrikimą bei imtis intervencijos, klinicistas turi atpažinti rizikos veiksnius, ištirti aplinkybes, situacijas ir šeimos kontekstą, kuriame šis sutrikimas pasireiškia.

3. Paskyrus gydymą, šeimos (vaikų) gydytojas privalo stebèti pediatrini pacientą dèl gydymo efektyvumo bei nepageidaujamo poveikio.

Kai reikia, pasitelkti kitų sveikatos priežiūros specialistų pagalbą.

\section{Literatūra}

1. Love AS, Love R. Anxiety disorders in primary care settings. The Nursing Clinics of North America 2019;54(4):473-93.

https://doi.org/10.1016/j.cnur.2019.07.002

2. Bhatia MS, Goyal A. Anxiety disorders in children and adolescents: need for early detection. Journal of Postgraduate Medicine 2018;64(2):75-6.

https://doi.org/10.4103/jpgm.JPGM_65_18

3. Wehry AM, Beesdo-Baum K, Hennelly MM, Connolly SD, Strawn JR. Assessment and treatment of anxiety disorders in children and adolescents. Current Psychiatry Reports 2015;17(7):52.

https://doi.org/10.1007/s11920-015-0591-z

4. Bhatia MS, Goyal A. Anxiety disorders in children and adolescents: need for early detection. Journal of Postgraduate Medicine 2018;64(2):75-6.

https://doi.org/10.4103/jpgm.JPGM_65_18

5. Fisher PH, Tobkes JL, Kotcher L, Masia-Warner C. Psychosocial and pharmacological treatment for pediatric anxiety disorders. Expert Review of Neurotherapeutics 2006;6(11):1707-19. https://doi.org/10.1586/14737175.6.11.1707

6. Salum GA, Desousa DA, do Rosário MC, Pine DS, Manfro GG. Pediatric anxiety disorders: from neuroscience to evidencebased clinical practice. Revista Brasileira de Psiquiatria (Sao
Paulo, Brazil:1999) 2013;35 Suppl 1:S03-21.

https://doi.org/10.1590/1516-4446-2013-S108

7. Essau CA, Lewinsohn PM, Lim JX, Ho MR, Rohde P. Incidence, recurrence and comorbidity of anxiety disorders in four major developmental stages. Journal of Affective Disorders 2018;228:248-53.

https://doi.org/10.1016/j.jad.2017.12.014

8. Cabral MD, Patel DR. Risk factors and prevention strategies for anxiety disorders in childhood and adolescence. Advances in Experimental Medicine and Biology 2020;1191:543-59.

https://doi.org/10.1007/978-981-32-9705-0_27

9. Ohannessian CM, Milan S, Vannucci A. Gender differences in anxiety trajectories from middle to late adolescence. Journal of Youth and Adolescence 2017;46(4):826-39.

https://doi.org/10.1007/s10964-016-0619-7

10. Pop-Jordanova N. Different Clinical Expression of Anxiety Disorders in Children and Adolescents: Assessment and Treatment. Pril (Makedon Akad Nauk Umet Odd Med Nauki). 2019 May 1;40(1):5-40.

http://doi.org/10.2478/prilozi-2019-000

11. Panganiban M, Yeow M, Zugibe K, Geisler SL. Recognizing, diagnosing, and treating pediatric generalized anxiety disorder. JAAPA 2019;32(2):17-21.

https://doi.org/10.1097/01.JAA.0000552719.98489.75

12. Wehry AM, Beesdo-Baum K, Hennelly MM, Connolly SD, Strawn JR. Assessment and treatment of anxiety disorders in children and adolescents. Current Psychiatry Reports 2015;17(7):52.

https://doi.org/10.1007/s11920-015-0591-z

13. Ströhle A, Gensichen J, Domschke K. The diagnosis and treatment of anxiety disorders. Deutsches Arzteblatt International 2018;155(37):611-20.

https://doi.org/10.3238/arztebl.2018.0611

14. LR SAM 2005 m. gruodžio 22 d. ịsakymas Nr. V-1013 Dèl Lietuvos medicinos normos MN 14:2005, Šeimos gydytojas. Teisès, pareigos, kompetencija ir atsakomybë“ patvirtinimo. Aktuali redakcija nuo 2019-05-01 Nr. V-328 Dèl Lietuvos medicinos normos MN 14:2019, „Šeimos gydytojas“ patvirtinimo.

15. Strawn JR, Lu L, Peris TS, Levine A, Walkup JT. Research review: pediatric anxiety disorders - what have we learnt in the last 10 years. Journal of Child Psychology and Psychiatry, and Allied Disciplines 2021;62(2):114-39.

https://doi.org/10.1111/jcpp.13262

16. Dodd HF, Hudson JL. Parent-child CBT reduces anxiety disorders among children aged 4-7 years. Evidence-Based Mental Health 2011;14(1): 18 .

https://doi.org/10.1136/ebmh1127

17. Jiang Z, Wang J, Yu X, Li C, Shao Y, Wang Z. Comparative efficacy and safety of traditional Chinese patent medicine for anxiety disorders in children or adolescence: a protocol 
for systematic review and network meta-analysis. Medicine 2020;99(39):e22274.

https://doi.org/10.1097/MD.0000000000022274

18. Dwyer JB, Bloch MH. Antidepressants for pediatric patients. Current Psychiatry 2019;18(9):26-42F.

19. Strawn JR, Mills JA, Sauley BA, Welge JA. The impact of antidepressant dose and class on treatment response in pediatric anxiety disorders: a meta-analysis. Journal of the American Academy of Child and Adolescent Psychiatry 2018;57(4):235244.e2.

https://doi.org/10.1016/j.jaac.2018.01.015

20. Southammakosane C, Schmitz K. Pediatric psychopharmacology for treatment of adhd, depression, and anxiety. Pediatrics 2015;136(2):351-9.

https://doi.org/10.1542/peds.2014-1581

21. Strawn JR, Dobson ET, Giles LL. Primary pediatric care psychopharmacology: focus on medications for ADHD, depression, and anxiety. Current Problems in Pediatric and Adolescent Health Care 2017;47(1):3-14.

https://doi.org/10.1016/j.cppeds.2016.11.008

22. Antonuccio D. Treating Depressed Children With Antidepressants: More Harm than Benefit? J Clin Psychol Med Settings 2008; 15:92-97.

https://doi.org/10.1007/s10880-008-9108-9

23. Valstybinè vaistų kontrolès tarnyba prie Lietuvos Respublikos sveikatos apsaugos ministerijos. Zoloft: Preparato charakteristikų santrauka. Vilnius.

https://vapris.vvkt.lt/vvkt-web/public/medications/view/11457

PEDIATRIC ANXIETY DISORDERS

IN GENERAL PRACTICE

K.Tarasevičiūtè, G. Poškutė

Keywords: children, adolescent, anxiety, fear, medication, psychotherapy.
Summary

Anxiety disorders are common and tend to recur in children and adolescents. If left untreated, they slow down both socio-emotional and cognitive development. Early identification and appropriate act are essential in general practice. To diagnose anxiety disorder, it is necessary to assess the risk factors, circumstances, situations, and family context in which it occurs. It is also important to distinguish between the normal development of children's fears and to recognize the pathological anxiety that disrupts daily activities and impedes the experiences required for normal development. If a general practitioner suspects or diagnoses anxiety disorders, he may turn to other health care professionals or, in accordance with the family doctor's norm, prescribe treatment himself. Effective interventions for these pathologies, such as: psychotherapy, psychopharmacotherapy, are being investigated. Cognitive behavioral therapy has been shown to be effective in preventing the onset of pathological anxiety and treating it without adverse effects. Still, medication is sometimes needed. Selective serotonin reuptake inhibitors (SSRIs) are classified as first-line drugs due to the positive benefit-risk balance. The State Medicines Control Agency under the Ministry of Health of the Republic of Lithuania has warned about the possible risk of suicide, behavioral changes and somatic complaints caused by SSRI treatment. Therefore, when choosing a form of medication, the patient's parents should be warned about possible side effects and consent to treatment should be obtained. This article discusses in detail the risk factors, diagnosis, and possible treatment tactics for anxiety disorders in children and adolescents.

Correspondence to: gertrudaposkute@gmail.com

Gauta 2021-05-05 